\title{
Ability of $\mathrm{B}_{12} \mathrm{~N}_{12}$ fullerènes like nano-cage for sensing and improving the antioxidant activity of juglone and its derivative: DFT investigation
}

\author{
Vincent de Paul Zoua ${ }^{1}$, Aymard Fouegue ${ }^{2}$, Désiré Mama ${ }^{3}$, Julius Ghogomu ${ }^{4}$, and Rahman \\ Abdoul Ntieche ${ }^{5}$ \\ ${ }^{1}$ University of Maroua \\ ${ }^{2}$ Higher Teacher Training College Bertoua, University of Ngaoundere \\ ${ }^{3}$ Faculty of Science, University of Douala \\ ${ }^{4}$ Faculty of Science, University of Dschang \\ ${ }^{5}$ The University of Ngaoundéré
}

July 6, 2021

\begin{abstract}
Density functional theory (DFT) calculations were adopted in this work to investigate the ability of the B12N12 fullerene like nano-cage for sensing juglone (Jug) and one of its derivative (Jug-OH) using DFT based methods in gas phase, pentyl ethanoate (PE) and water. Results showed that B12N12 is able to adsorbed Jug preferentially by binding to one of the O-atom of its carbonyl groups. Based on NBO analysis, a charge transfer from the oxygen atoms of Jug and Jug-OH to the anti-bonding orbital of B was revealed. QTAIM analysis showed that the B12N12-Jug and B12N12-Jug-OH complexes are stabilized by a partially covalent B-O bond in addition to attractive non covalent interactions. The ability of Jug, Jug-OH as well as their complexes A and A-OH to scavenge radicals has been investigated via the usual hydrogen atom transfer (HAT) mechanism in the three media of study previously stated. Theoretical results revealed that in PE and water, the complexes are better antioxidant than Jug and Jug-OH. These results provide fundamental knowledge for the development of new antioxidant delivery careers.
\end{abstract}

\section{Hosted file}

IJQC.docx available at https://authorea.com/users/424075/articles/529239-ability-of-b12n12fuller\%C3\%A8nes-like-nano-cage-for-sensing-and-improving-the-antioxidant-activity-ofjuglone-and-its-derivative-dft-investigation 